- Revista de Iniciação à Docência, v. 5, n. 2, 2020 -

Publicação: agosto, 2020 - ISSN 2525-4332

\title{
A UTILIZAÇÃO DE JOGOS EDUCATIVOS NO CONTEXTO DE UMA MELHOR APRENDIZAGEM: RELATO DE EXPERIÊNCIA
}

Amanda Caroline Biazon ${ }^{1}$ Alessio Gava ${ }^{2}$

\begin{abstract}
RESUMO: Recorrer a atividades lúdicas na área do ensino, como por exemplo utilizar jogos em sala de aula, é hoje em dia uma prática cada vez mais comum. Neste artigo é relatada uma experiência realizada no âmbito do PIBID em um colégio estadual do interior do Paraná, derivando algumas conclusões sobre a utilização e a contribuição dos jogos matemáticos nas práticas de ensino e aprendizagem de crianças e jovens, assim como sobre a importância desses recursos e estratégias didáticas como objeto de aprendizagem e fixação do conhecimento.
\end{abstract}

Palavras-Chave: Ensino-Aprendizagem; Jogos Matemáticos; Práticas de Ensino.

ABSTRACT: Employing recreational activities in the teaching field, such as playing educational games in class, is nowadays a common practice. In this paper, an experience that took place in a state college in Paraná, as part of the PIBID program, will be presented. Considerations about the use and the contribution of Maths games in the teaching-learning process, together with a reflection on the importance of these resources and didactic strategies as learning object and reinforcement, will also be proposed.

Keywords: Maths Games; Teaching Practices; Teaching-Learning Process.

\section{Introdução}

O Programa Institucional de Bolsas de Iniciação à Docência - PIBID busca inserir estudantes de cursos de licenciatura nas escolas públicas de educação básica, para que eles tenham contato com a prática docente em sala de aula e assim criem um vínculo com as instituições de ensino. Trata-se, em outras palavras, de um projeto que visa incentivar a formação de professores. Vale a pena salientar que tal programa é de extrema importância para acadêmicos das licenciaturas, pois através das atividades desenvolvidas os discentes podem compreender a importância de ter um contato precedente com a didática em sala de aula antes mesmo de concluir a graduação.

Ao longo dos anos, todavia, vários fatores têm tornado o ser professor uma tarefa cada vez mais desafiadora: a desvalorização da profissão, a falta de recursos básicos e até mesmo a falta de tempo para estudos e planejamento. Isso evidentemente acarreta uma série de consequências negativas, como por exemplo a defasagem no ensino e as dificuldades de se cumprir o currículo escolar.

\footnotetext{
${ }^{1}$ Graduanda e bolsista PIBID do curso de Licenciatura em Matemática, Universidade Estadual do Paraná Campus Apucarana. Contato: amandcsouza@gmail.com

${ }^{2}$ Docente do curso de Licenciatura em Matemática, Universidade Estadual do Paraná - Campus Apucarana. Contato: alessiogava@yahoo.it
} 
Nessa perspectiva, visto que o horizonte deste estudo é o ensino-aprendizagem da Matemática, não podemos deixar de pensar nesse processo e na forma como tal área de conhecimento é vista pela sociedade em geral: como um âmbito de estudos complexos e desafiadores, a ponto de muitos alunos a repudiarem, deixando em desvantagem o ensino e a vontade de aprender; e, nas palavras de Augusto Cury, "nada é mais frustrante do que ensinar para quem não quer aprender" (CURY, 2006, p. 93).

Tal visão acerca da 'ciência dos números' cria frequentemente uma barreira entre o ensino e a aprendizagem, o que muitas vezes torna o processo doloroso tanto aos alunos quanto aos professores. Diante dessa situação, é mister despertar nos discentes o interesse pela Matemática, por exemplo, mostrando que ela está presente o tempo todo em nossas vidas e em nosso cotidiano.

Neste artigo serão descritos e comentados alguns jogos utilizados em oficinas educativas que foram introduzidas em sala de aula como forma lúdica, incentivadora e inovadora de aprender brincando. Sobre esse modo de despertar o interesse e a vontade pelo saber matemático, Flemming e Collaço de Mello assim se expressam:

\begin{abstract}
Vale mencionar que esse recurso deve ser adotado em sala de aula e que a aprendizagem de conteúdo poderá acontecer de forma mais dinâmica, menos traumática, mais interessante. Acreditamos que o jogo contribui para que o processo ensino-aprendizagem seja produtivo e agradável tanto para o educador quanto para o educando (FLEMMING; MELLO, 2003, p. 85).
\end{abstract}

\title{
2. Atividades Desenvolvidas no Projeto
}

O projeto aqui apresentado, executado no Colégio Estadual “Antônio dos Três Reis de Oliveira" de Apucarana/PR, durante o ano de 2019, tinha como público-alvo os alunos do $7^{\circ}$ ano (Ensino Fundamental II) da referida escola. Os conteúdos nele trabalhados foram: números decimais, números positivos e negativos e o conceito de volume. Para tanto, foram desenvolvidos um jogo de compras, um jogo de ping-pong e uma oficina para confecção de alguns personagens do jogo Minecraft.

A seguir, será inicialmente apresentada uma descrição de cada uma das atividades aplicadas e, posteriormente, serão tecidas reflexões acerca dos resultados obtidos no projeto.

\section{1 - Jogo de compras:}

Esse jogo foi desenvolvido a partir da ideia de que os alunos em geral têm grande interesse por jogos relacionados a dinheiro e compras, sendo esse um conteúdo com o qual se identificam muito, por fazer parte do dia-a-dia de cada um.

O jogo tem por objetivo fixar o conceito de números decimais, buscando estabelecer uma relação entre o conteúdo estudado em Matemática e o jogo, e também com a prática e a utilização desses no cotidiano, assim como auxiliar os alunos a reconhecerem os números decimais, realizarem somas e subtrações de números decimais, trabalharem o sistema monetário brasileiro, aprenderem a utilizar o dinheiro para realizar 
- Revista de Iniciação à Docência, v. 5, n. 2, 2020 -

Publicação: agosto, 2020 - ISSN 2525-4332

compras e conferir troco, construírem ligações entre os conceitos matemáticos e sua aplicação prática no cotidiano e realizarem o arredondamento do valor das casas decimais de um número. Para tanto, cédulas e moedas falsas de papel foram confeccionadas com panfletos de supermercados.

Recursos materiais utilizados: 40 cartas com figuras de produtos de supermercado e seus respectivos valores, um tabuleiro de saída e chegada e cédulas e moedas falsas de papel.

\section{Modo de jogar:}

- A turma foi dividida em grupos de cinco alunos cada;

- Foram entregues a cada grupo as cartas e o tabuleiro e individualmente cada jogador recebeu uma cédula de $\mathrm{R} \$ 50,00$;

- Cada grupo contou com auxílio e orientações de um Pibidiano que ficou responsável pelo caixa do jogo, para receber o dinheiro e dar o troco aos jogadores.

- Cada grupo embaralhou suas cartas e as deixou em monte sobre a mesa, com as faces viradas para baixo; em seguida, foi selecionado um aluno para que o jogo começasse.

- O jogador da vez era convidado a retirar uma carta do monte, analisar o produto e comunicar aos demais jogadores se desejaria comprá-lo ou não. Caso optasse por realizar a compra, deveria, com auxílio de papel e lápis, fazer as contas acerca do valor que iria pagar e do troco que deveria receber. Caso optasse por não realizar a compra, a carta deveria ser descartada.

- O jogo continuaria assim a desenvolver-se sucessivamente.

- O vencedor seria o jogador que primeiro comprasse cinco itens do mercado; no caso em que, ao final da rodada, mais de um aluno estivesse com 5 itens, venceria aquele que estivesse com a maior quantidade de dinheiro.

Observação: cada rodada terminava apenas quando todos os alunos do grupo tivessem jogado.

Resultados obtidos: o que se esperava com essa atividade seria que os discentes fossem capazes de reconhecer os números decimais e realizar as operações de soma e subtração, assim como associar a utilização dessas simulações com as atividades cotidianas. De imediato, o jogo atendeu tanto às expectativas dos alunos, quanto da professora e revelou-se uma atividade prazerosa e desafiadora, que os alunos se empenharam em realizar e na qual também se esforçaram para ajudar os colegas que eventualmente aparentassem estar com um pouco mais de dificuldades. Acreditamos ser de suma importância que os discentes sejam capazes de estabelecer relações de cooperação em grupo, pois esse processo faz parte da didática de ensinar e aprender.

As figuras 1 e 2, apresentadas na sequência, ilustram os estudantes participantes do projeto durante a atividade de aplicação do jogo de compras. 
- Revista de Iniciação à Docência, v. 5, n. 2, 2020 -

Publicação: agosto, 2020 - ISSN 2525-4332

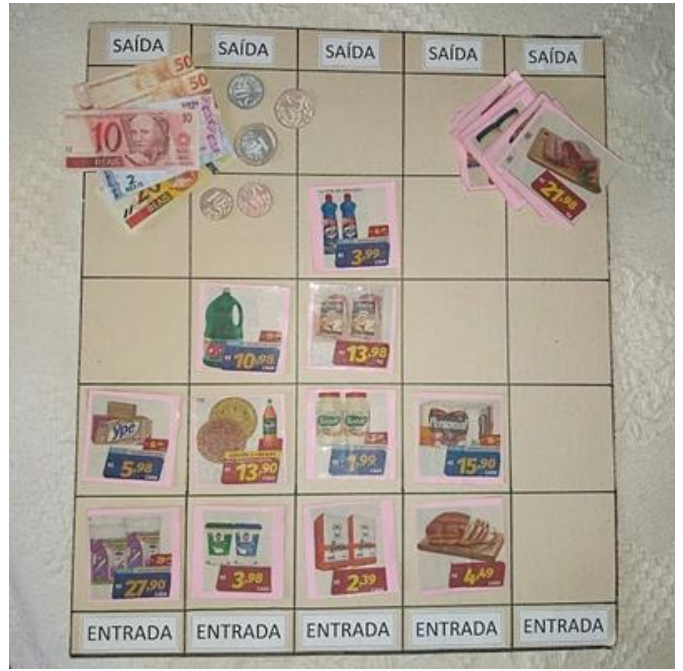

Figura 1: Tabuleiro e peças do jogo.

Fonte: autores

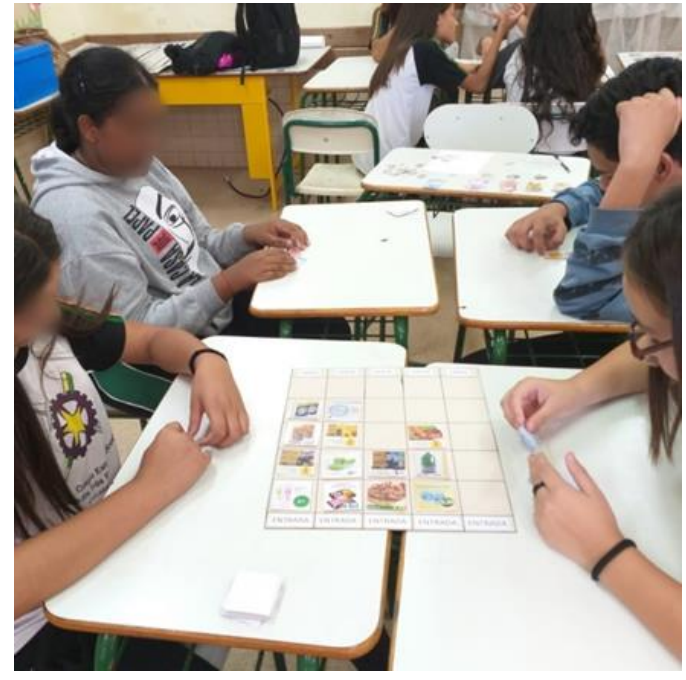

Figura 2: Alunos jogando.

Fonte: autores

\section{2 - Ping-pong dos números positivos e negativos:}

A ideia de aplicar esse jogo surgiu após verificarmos que os alunos estavam com dificuldades em compreender as operações de soma e subtração com números positivos e negativos e quando eles tentavam fazer comparações entre eles.

O jogo tem como objetivo principal o de fixar esses conceitos, bem como auxiliar os alunos quanto a compreender e reter as regras de sinais para a adição e subtração de números positivos e negativos. Em relação a esse segundo tópico, como bem se sabe, temos que, no caso da adição:

- Sinais iguais: somam-se os (módulos dos) números e conserva-se o sinal.

- Sinais diferentes: subtraem-se os (módulos dos) números e conserva-se o sinal do maior (em módulo).

No caso da subtração, diversamente, basta lembrar que subtrair um número é o mesmo que somar o oposto desse, o que remete às regras acima inclusive no caso da operação inversa da adição.

Recursos materiais utilizados: bolinhas de ping-pong, tabuleiro confeccionado com caixas de ovos, contendo 30 números positivos na cor azul e 30 números negativos na cor vermelha, tabela impressa a ser completada, lápis e borracha.

Observação: no jogo, a identificação dos números positivos ou negativos se deu apenas pela cor, ou seja, os negativos não tinham sinal de 'menos' (-) na frente; do mesmo modo, os positivos não tinham sinal de 'mais' (+).

Desenvolvimento do jogo: a atividade foi realizada no ambiente externo do Colégio, buscando sairmos um pouco da monotonia das aulas, e tentando mostrar aos alunos que o conhecimento ofertado pelas instituições de ensino não se restringe apenas 
ao espaço específico de uma sala de aula, mas está em todo lugar. Assim, os tabuleiros confeccionados e as bolinhas de ping-pong foram dispostos sobre mesas, os alunos divididos em seis grupos e a cada aluno foi entregue uma tabela. Os integrantes de cada grupo disputaram o jogo entre si.

\section{Modo de jogar:}

- $\quad$ O primeiro jogador (e assim como os outros, em seguida, um de cada vez) deve pegar as bolinhas, uma por uma, e jogá-las sobre a mesa com objetivo de acertar o tabuleiro. Caso em um dos lances não acerte o alvo, deverá jogar de novo a bola até acertar.

- $\quad$ Após ter exaurido as bolinhas, deve verificar quais números acertou em sua jogada e verificar se são positivos ou negativos (azul/vermelho) e marcá-los em sua tabela fazendo a soma ou subtração dos valores obtidos.

- $\quad$ jogo continua por cinco rodadas.

- $\quad$ Após o término deste processo, os alunos se reúnem para fazer a soma dos resultados obtidos. Cada jogador calcula o total dos resultados dos próprios lances e esse será seu resultado final.

- $\quad$ Por fim, os jogadores fazem a comparação entre os totais de cada integrante do grupo, ordenando os mesmos, da pontuação maior até a menor. É considerado vencedor do jogo o aluno que conseguir a maior pontuação.

Resultados obtidos: conforme foi dito anteriormente, esse jogo foi pensado após percebermos que os alunos estavam com dificuldades em compreender a utilização dos números negativos e positivos. Graças à atividade desenvolvida, foi possível perceber que os discentes alcançaram um melhor entendimento de tal utilização. Outro ponto positivo foi o fato de se tratar de uma atividade extraclasse, o que gerou grande euforia e interesse pelos conteúdos, levando os alunos a obterem ótimos resultados e a quererem aprender. As Figuras 3 e 4, apresentadas na sequência, ilustram os estudantes participantes do projeto durante a atividade de aplicação do jogo ping-pong.

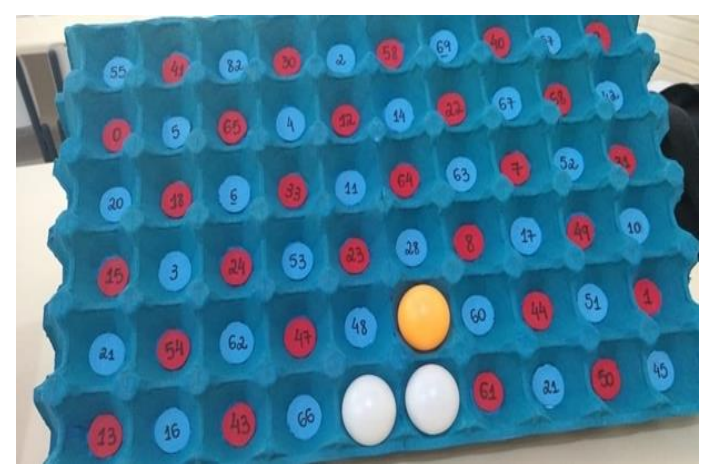

Figura 3: Tabuleiro do jogo ping-pong. Fonte: autores

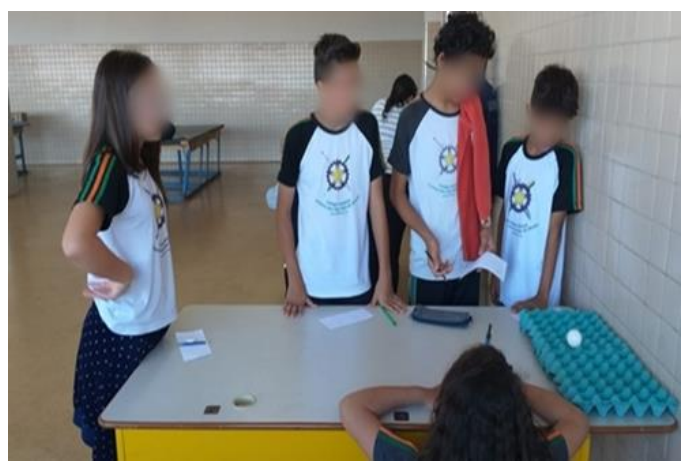

Figura 4: Alunos jogando. Fonte: autores 
- Revista de Iniciação à Docência, v. 5, n. 2, 2020 -

Publicação: agosto, 2020 - ISSN 2525-4332

\section{3 - Oficina dos personagens do jogo Minecraft:}

A ideia dessa oficina surgiu após a reflexão segundo a qual seria oportuno introduzir nas aulas algo com o qual os alunos se identificassem e que fizesse parte da vida deles. Assim, foi proposto aos alunos confeccionar, com cubos de papel, os personagens do jogo Minecraft, para que posteriormente esses fossem utilizados para destacar os elementos e a medida do volume de um cubo. O Minecraft é um jogo bastante conhecido pelos jovens, que pode ser jogado no computador, por meio de uma console e até mesmo no celular. Consiste, basicamente, em construir objetos utilizando apenas blocos. O interessante do jogo é que não há uma maneira correta de ser realizado, ou seja, o jogador pode aventurar-se nele decidindo o que fazer da maneira que mais gosta.

Recursos materiais utilizados: molde de cubos em folhas de sulfite, tesoura, cola branca, tinta guache, pincel, papel dobradura, papel craft e régua.

Desenvolvimento da oficina: no início da atividade, cada aluno recebeu uma folha contendo dois moldes de cubo, para que os recortasse, dobrasse e colasse, de modo a construir os dois sólidos. Em seguida, foi proposto que se formassem grupos de até cinco alunos para que eles, trabalhando em conjunto, utilizassem os cubos para a confecção dos personagens. Com auxílio da professora e dos pibidianos, foi escolhido, para cada grupo, o personagem a ser montado.

Assim, deixou-se que os alunos montassem e colassem os cubos uns nos outros, de modo a formar o corpo do personagem; em seguida, foram entregues tinta guache e pincel para que eles pudessem pintá-lo. Durante essa etapa, aproveitou-se para chamar a atenção sobre quantos cubos foram utilizados na confecção de cada boneco, relembrando que cada cubo tem elementos (arestas, vértices e faces) e também um volume. Foi explicado aos alunos que o volume é a quantidade de espaço ocupado por um corpo e que aquele, referente a um cubo, dependia da medida de suas arestas, que no caso, eram todas iguais. A fórmula para calcular o volume de um cubo é:

$\mathbf{V}=\mathbf{a}^{3}$, onde $\mathbf{a}$ corresponde à medida da aresta (lado de cada face) do cubo.

Enfim, com os bonecos já pintados e devidamente colados, foram entregues papeis dobradura coloridos, que foram utilizados pelos alunos para finalizar os últimos detalhes dos personagens, tais como olhos, boca, cabelo etc. Após o término da atividade, os bonecos foram dispostos em uma maquete e expostos na Mostra Cultural do Colégio.

Resultados obtidos: essa oficina fugiu um pouco da monotonia das aulas normais de Matemática: aparentemente não havia conceitos da disciplina envolvidos na confecção dos bonecos, os alunos adoraram a ideia de realizar a atividade e se mostraram dispostos a obter um bom resultado, tanto no trabalho em equipe, quanto no resultado final. No momento em que foram apresentados os conteúdos 
matemáticos subjacentes à atividade, foi possível perceber que os discentes tiveram um pouco de dificuldade para relembrar quais são os elementos do cubo. Após esse processo de 'retomada', percebemos que eles compreenderam o assunto de modo mais eficaz, o que auxiliou para uma aquisição e um entendimento "mais suaves" do conceito de volume do cubo. Em suma, pode-se dizer que a oficina atendeu às expectativas e trouxe bons resultados. As figuras 5, 6 e 7, apresentadas na sequência, ilustram os estudantes participantes do projeto durante a oficina Minecraft.

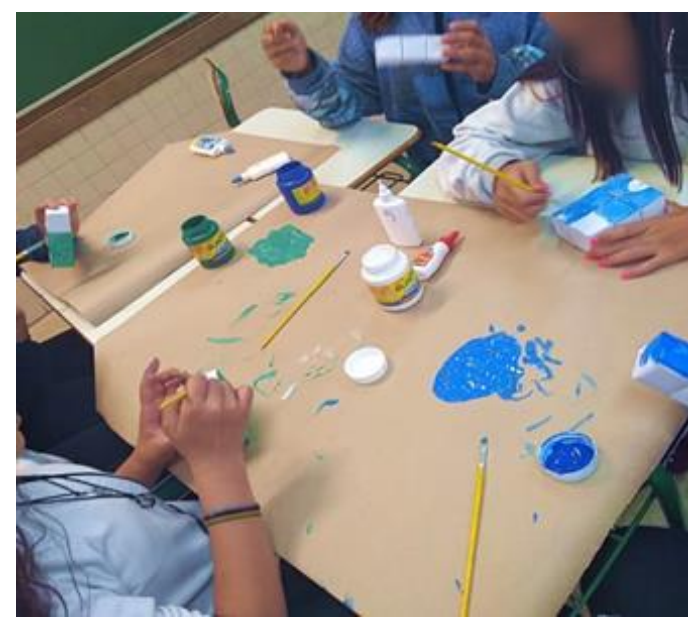

Figura 5: Confecção dos personagens. Fonte: autores

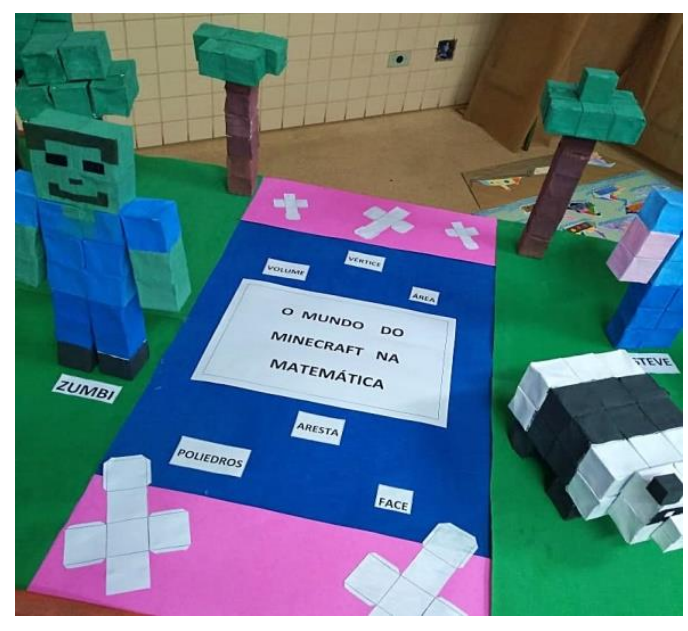

Figura 6: Maquete.

Fonte: autores

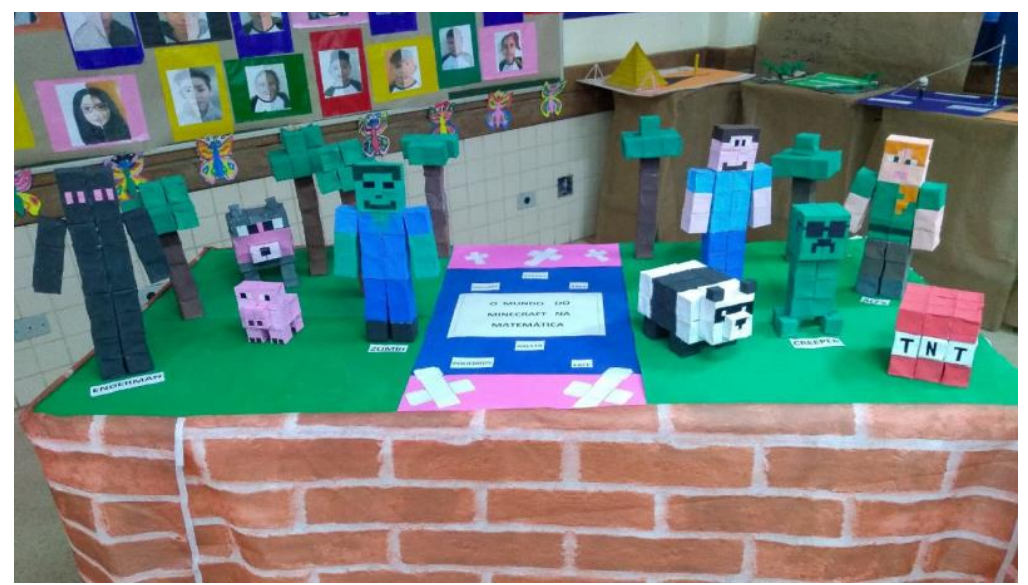

Figura 7: Maquete. Fonte: autores.

\section{Conclusão}

A nosso ver, a utilização de atividades lúdicas como complementação das práticas educativas proporciona a professores e educandos uma forma abrangente e de fácil aplicação de transmitir e adquirir conhecimento, ao mesmo tempo em que torna o processo mais instigante para os estudantes. Evidentemente, porém, é necessário filtrar com cautela o que deve ou não deve ser inserido como atividade em sala de aula, pois da mesma forma em que os jogos vêm para complementar outras 
formas de ensino, podem também surtir efeito contrário, quando não utilizados de maneira adequada.

Segundo Cabral (2006), “devemos utilizá-los não como instrumentos recreativos na aprendizagem, mas como facilitadores, colaborando para [a remoção dos] bloqueios que os alunos apresentam em relação a alguns conteúdos matemáticos" (p. 29, grifo dos autores). Em outras palavras, ao propor tais práticas, deve-se buscar não apenas um momento de recreação, mas também - e principalmente - uma forma alternativa de aquisição de conhecimentos matemáticos.

Durante a aplicação dessas estratégias de ensino, desenvolvidas no âmbito do Pibid no Colégio Estadual "Antônio dos Três Reis de Oliveira" de Apucarana/PR, foi possível notar que além de os alunos adquirirem com maior facilidade e eficácia os conteúdos matemáticos, também desenvolveram um trabalho de cooperação em equipe, sempre ajudando uns aos outros para que a atividade acontecesse. Esse aspecto também é de suma importância dentro de um ambiente escolar, cuja função de socialização pode ser considerada não menos importante - ou talvez parte imprescindível - daquela de formação intelectual dos discentes.

Starepravo relata essa situação do professor em utilizar suas aulas com a inserção dos jogos:

O professor, ao preparar suas aulas com a utilização de jogos deve escolher técnicas para uma exploração de todo o potencial do jogo; também deve analisar as metodologias adequadas ao tipo de trabalho que pretende, tais como: a melhor maneira de organizar os grupos e a seleção de jogos que sejam adequados ao conteúdo que se pretende trabalhar. $O$ trabalho com jogos requer do professor certas atitudes que o levem a considerar como uma atividade a ser realizada durante todo o ano letivo, e não de modo esporádico, relacionando o jogo como uma estratégia aliada à construção do conhecimento, devendo planejar cuidadosamente sua execução (STAREPRAVO, 1999 apud BARBOSA; CARVALHO, 2009, p. 7).

Enfim, a nosso juízo, os jogos são ótima alternativa para sair um pouco da monotonia da sala de aula e podem ser empregados sempre que necessário, já que constituem uma forma mais divertida de aprender brincando. Por isso, devemos pensar além da sala de aula e sermos motivadores em nossas propostas, buscando sempre despertar nos educandos o desejo pelo saber matemático.

\section{4 - Referências}

BARBOSA, S. L. P.; CARVALHO, T. O. Jogos Matemáticos como Metodologia de Ensino Aprendizagem das Operações com Números Inteiros. Programa de Desenvolvimento da Educação. Londrina/PR, 2009.

Disponível em: <http://www.diaadiaeducacao.pr.gov.br/portals/pde/arquivos/1948-8.pdf>. Acesso em: 15/10/2019.

CABRAL, M. A. A utilização de jogos no ensino de matemática. Trabalho de Conclusão de Curso, Universidade Federal de Santa Catarina. Florianópolis/SC, 2006.

CURY, A. Filhos brilhantes Alunos fascinantes. Rio de Janeiro/RJ: Sextante, 2006. 
- Revista de Iniciação à Docência, v. 5, n. 2, 2020 -

Publicação: agosto, 2020 - ISSN 2525-4332

FLEMMING, D. M.; COLLAÇO DE MELLO, A. C. Criatividade Jogos Didáticos. São José: Saint-Germain, 2003.

STAREPRAVO, A. R. Jogos, desafios e descobertas: o jogo e a matemática no ensino fundamental - séries iniciais. Curitiba/PR: Renascer, 1999.

$* * *$

Recebido: $11 / 11 / 2019$

Aprovado: 04/06/2020 